\title{
Ranking of Financing Methods in Iran Construction Renovation Projects: A Sensitivity Analysis Approach
}

\author{
Vahidreza Yousefi $\mathrm{a}^{*}$ \\ Aida Rahimi Golkhandan ${ }^{b}$ \\ Sarmad Kianic \\ Siamak Haji Yakhchalid \\ Ehsan Mehrabanfare
}

\begin{abstract}
$a^{\star}$ PhD Candidate of Construction and Project Management, University of Tehran, Tehran, Iran; Email: vr.yousefi@ut.ac.ir b. PhD Candidate of Construction and Project Management, University of Tehran, Tehran, Iran; Email: ayda_rahimi@yahoo.com c. PhD Candidate of Construction and Project Management, University of Tehran, Tehran, Iran; Email: sarmadkiani@ut.ac.ir d. PhD. Assistant Professor, Industrial Engineering, University of Tehran, Tehran, Iran; Email: yakhchali@ut.ac.ir e. Faculty of Management, Science \& Technology, Amirkabir University of Technology, Tehran, Iran Email: e.mehrabanfar@gmail.com
\end{abstract}

\section{Doi:10.5901/mjss.2015.v6n5s2p303}

\section{Abstract}

In this paper, financing methods used in Tehran's Renovation Organization are identified. Through repeated analysis, a combination of criteria with largest impact on all finance methods is discovered. Henceforth, AHP (Analytic Hierarchy Process) method is used for selecting the optimal financing method among available alternatives and also is used for improving accuracy of results. Since the objective of the current paper is to offer a model for supporting the decision-making process, sensitivity analysis is carried out in the subsequent stage to determine impact of variation of scale weights in prioritization of different projects.

Keywords: AHP (Analytic Hierarchy Process), Sensitivity Analysis, Project Finance, Deteriorated Areas, Renovation Projects

\section{Introduction}

Using ordinary techniques, it is impossible or at least requires too long time to financially support the renovation and restoration projects of deteriorated areas including of renovators' concentrated projects which are studied in the current research and enjoy remarkable social significance due to their high risks and low investment attraction. Reliance of budget of these projects on financial credit and capability of Renovation Organization, as the sponsor, is insufficient for meeting their financial requirements, which endangers fates of these projects. Hence, it is vital to divert some percentage of participants' expectations to performance and outcome of project for finance of these projects. To make decisions concerning the mechanism of providing financial resources of these projects, Renovation Organization as the sponsor of the understudied projects needs a model which systematically takes into account the possible finance methods according to its priorities and expectations. This model shall determine a method or combination of methods to fulfill financial requirements and is supposed to appropriately control the risks of such projects. Objective of the current research is to identify and evaluate different scenarios of finance including:

- Participants in finance

- Tools of each one in finance

- Share of each one in amount of finance

- Time and amount of financial support

It also aims at finding the superior scenario using mathematical decision-making techniques in uncertainty conditions and different projects. 


\section{Basics of Financing}

Since no project is performed without financing and the financial planning begins at the time feasibility measurement, designing the project strategy will be affected by the project financing method. The most successful projects are those that their financial planning are considered as a part of project strategy from the beginning, and the project objective is to minimize the costs of the project life cycle [Turner, $R, 2007]$.

The project financing requires exact financial engineering to allocate the risks and opportunities among the project stakeholders in a way that would be plausible and convincing to the parties. The figure below shows the basic elements of project financing [Finnerty, J.D, 1996].

There are always two basic options for financing the project: financing through the capital of shareholders (equity), and financing by loan or debt method (debt). It should be noted that there is not always a clear distinction between these two options, and a continuum of equity to debt can be considered according to the financing structure as follows: [Turner, R, 2007], [Yescombe, E, 2002], [Gatti, S, 2008], [Fight, A, 2006].

- In case of financing through equity, investors or shareholders will receive the dividends or the capital growth of their equities according to value of their shares. In this case, there is no guarantee for dividends to be paid or even the return of the original money. Dividends are paid only when the debt obligations have been reimbursed in scheduled deadlines and all the requirements of lenders have been met.

- Subordinate debts are loans that are funded by shareholders. This type of financing sometimes is considered such as stocks. For this reason, it is also called Mezzanine debt. This type of financing has some differences compared to equity. It will be reimbursed at specific timing, and the reimbursement to providers is as payment with predetermined interest.

- The Senior debt is the money that is loaned from a number of possible funding sources, especially banks, which can be reimbursed in scheduling agreement considering the predetermined interest. The senior debt has two types:

- Secured debts: These loans are guaranteed with collateral properties or assets and can be easily converted to cash. These resources are loaned to Parent organization and are guaranteed by some properties; no matter spent in which project, they can be repaid.

- Unsecured debts: This type of loan is granted only for a specific project, and will be just guaranteed against the assets of the project and the anticipated revenue flow of the project. This type of loan is a non- guaranteed type of financing, without recourse and out of balance sheet and it is independent of the success of the project.

\subsection{Risk and finance}

According to research scope of the present study, some part of decision-making criteria in selection of finance method for the understudied projects is based on capability of each alternative in covering the risks of the projects. Projects are conceptually linked to future, and due to ambiguity in future, upcoming events cannot be precisely determined based on past information, and, research analyst is unable to predict them confidently. Thus, financial analysis and evaluation shall be done under risk conditions and uncertainty. Prediction of future commercial environment, demand, production and sales becomes possible through estimation. In fact, all items involved in investment evaluation are ambiguous and uncertain, including: marketing and sales program, selection of inputs and project implementation site, technology selection, engineering design, management, personnel, and project execution organization.

The risks taken into account in finance of projects shall be specific for the same project which is financially supported. However, extent of project risks has been studied in different classifications. Finnerty believes that project risk include completion risk, technological risk, raw material supply risk economical risk, financial risk, currency risk, political risk, environmental risk, and force major risk [Finnerty, 1996].

Yescombe has classified project risks in three categories of political macro-risks, macro-economic risks, and commercial risks. Political risks (or country risks) are threats which depend on influences, behaviors, and actions of government or force major political events such as war and civil unrests. Marco-economical risks (financial risks) are threats associated with external economic transformations of plan like inflation, rate of interest, foreign exchange rate, and finally, commercial risks (also called "project risks") are threats related to nature of project and the production market. The following classification illustrates project risks (In Yescombe's attitude, 2002) 


\section{Methodology}

Analytic Hierarchy Process (AHP) is a decision-making method by which decisions dependent on several factors (multicriteria) can be made. Overall, this technique is used in problems of classification, selection, assessment, rating, and prediction, all of which require decision-making (Ghodsipour, 2001). AHP has been used in the fields of management, engineering, industry, government, education, politics, social analyses, sports, construction and manufacturing (Vaidya \& Kumar, 2006). Reasons for widespread usage of AHP can be attributed to: straightforward application, simplicity, and flexibility. AHP could be also applied continuously together with other techniques such as mathematical programming for analyzing not only the qualitative and quantitative factors but also the restrictions similar to real-world problems (Ho, 2008).

Application in project and construction management is another instance of vast usages of AHP. The instances of its application are: multi-criteria selection process of building components (Nassar, Thabet, and Beliveau, 2003), decision-making support system for selecting suitable method of project submission (delivery) using analytic hierarchy process (Mahdi \& Alreshaid, 2005), conventional construction process or advanced automation (Hastak, 1998), multicriteria assessment of winning chance in competitive tender process (Cagno, Caron, and Perego, 2001), and application in project management (pre-qualification of contractors) (Kamal, Al-Harbi, 2001), (El-Sawalhi, Eaton, and Rustom, 2007). Recently, focuses are on hybrid application of AHP and other means rather than AHP by itself. For example, AHP is used in combination with mathematical programming so as to take into account the qualitative and quantitative factors as well as resource limitations in reality $(\mathrm{Ho}, 2008)$.

To have a thorough literature review, an extensive library research including the review of existing books, papers, journals, and conducting interview with experts in the field of project finance was carried out. This preliminary list of project finance methods and criteria was further refined by interviews with academic experts and practicing professionals of deteriorated areas renovation projects. The result was a list comprising 10 financing methods and 7 criteria which confirmed by experts, construction project managers, scholars and academics involved in Renovation of Deteriorated Areas. The current work is an applied research in terms of objective. Regarding data collection mechanism, it is a descriptive study based on literature review, deductive reasoning, and model designing.

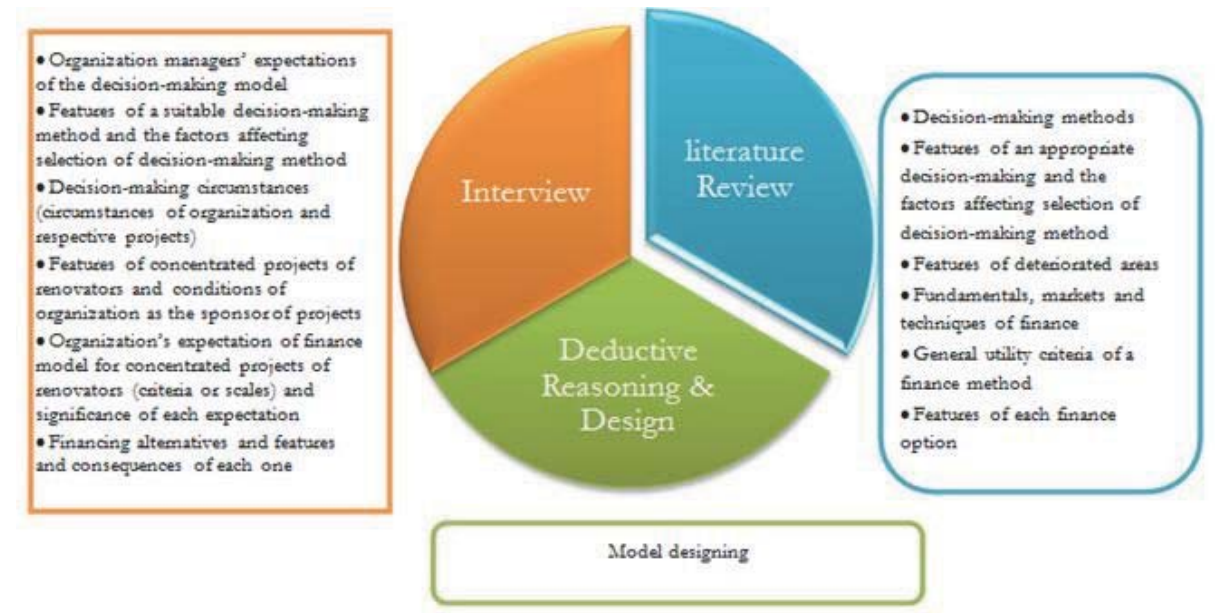

Figure 1. Tools of the current research

\section{Results and Discussion}

Analytic hierarchy process results are investigated in this part of research. Up to this point, all finance methods used in deteriorated areas have been analyzed and important factors for selecting each alternative have been explained as well. Different finance alternatives in deteriorated areas used as model input are introduced in the following table. 
Table 1. Project Finance Methods

\begin{tabular}{|l|}
\hline Project Finance Methods \\
\hline Issuance of investment papers of lands and buildings funds \\
\hline Receiving facilities from private banks \\
\hline Issuance of bonds \\
\hline Shareholder of the project \\
\hline Receiving facilities from public banks \\
\hline Issuance of mortgage bonds (Securitization) \\
\hline Issuance of Sukuk1 \\
\hline Pre-sale \\
\hline partnership with contractors \\
\hline Meter-sale of housing \\
\hline
\end{tabular}

The factors used as criteria for comparison of alternatives are collected in table 2.

Table 2. Important Criteria

\begin{tabular}{|l|}
\hline Criteria \\
\hline Financing costs \\
\hline Cost of capital \\
\hline Construction management costs \\
\hline Marketing and sales costs \\
\hline Level of achievement of resources \\
\hline Fulfillment of resources \\
\hline Minimum of negative impacts \\
\hline
\end{tabular}

In the subsequent steps, paired comparison is made for each two alternatives with respect to a certain scale; this procedure is performed for all alternatives with respect to all criteria (scales). Totally, using the formula:

$$
\frac{n(n-1)}{2}=\frac{10(10-1)}{2}=45
$$

45 comparisons will be made for comparing each pair of alternative with respect to a certain scale. Considering number of scales in the current study (7), totally $45 \times 7=315$ comparisons will be analyzed for each general judgment in this phase of research. Due to large number of judgments, inconsistency likelihood severely increases under such circumstances. Maximal acceptable inconsistency can be found from the table. CR value shall be lower than 0.1 in calculations of the current research. In this stage, it is tried to minimize inconsistency value by means of repeated judgment about comparisons which are poorly aligned. Finally, total value of inconsistency in all comparisons reached to 0.05 by repeating inconsistent judgments until their complete improvement.

This technique assigns score 1 to the alternative which has the highest significance in the corresponding scale and assigns a percentage of the superior alternative to other alternatives depending on their relative significances.

Table 3. Ranking of Project Finance Methods with Total Weights

\begin{tabular}{|c|l|l|}
\hline Priority & Project Finance Methods & Total Weight \\
\hline 1 & Receiving facilities from public banks & 0.186 \\
\hline 2 & Pre-sale & 0.136 \\
\hline 3 & Issuance of investment papers of lands and buildings funds & 0.125 \\
\hline 4 & partnership with contractors & 0.091 \\
\hline 5 & Issuance of bonds & 0.086 \\
\hline 6 & Shareholder of the project & 0.085 \\
\hline 7 & Meter-sale of housing & 0.080 \\
\hline 8 & Issuance of mortgage bonds (Securitization) & 0.074 \\
\hline 9 & Issuance of Sukuk & 0.072 \\
\hline
\end{tabular}

\footnotetext{
1 Sukuk is a type of fixed income security and is used in Islamic countries
} 


\subsection{Sensitivity Analysis}

Up to this stage, all alternatives of finance methods in renovation of deteriorated areas have been prioritized in terms of the respective criteria. In order to conduct comprehensive study on the current case, change of priority in each alternative shall be evaluated with variation in significance level of scales. Depending on the objective, sensitivity analysis indicates sensitivity degrees of alternatives with respect to criteria. This diagram shows that the priority the alternatives have in comparison with others with respect to each scale and also in general conditions. Left-hand side and right-hand side axes respectively represent scores of alternatives and significance of criteria.

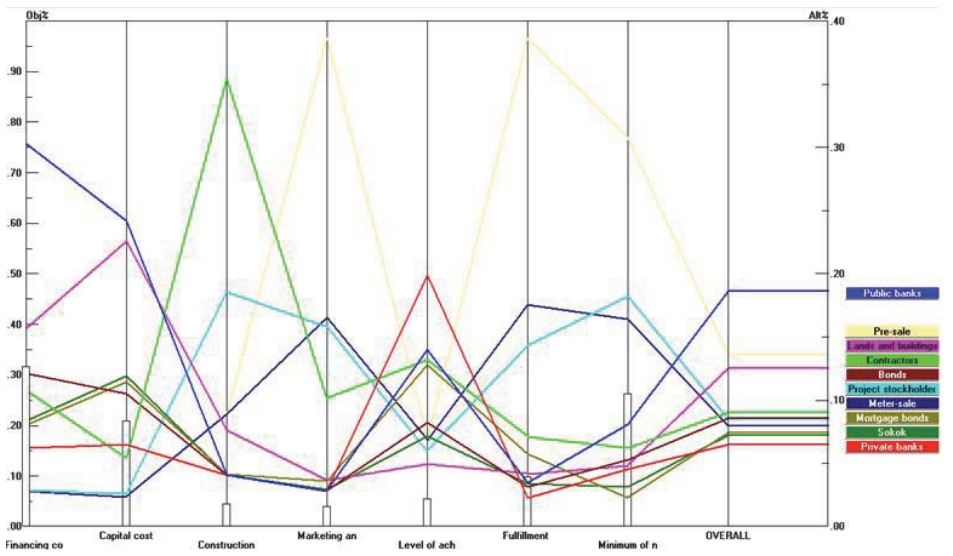

Figure 2. Tree-like Sensitivity Analysis

The impacts of changes in significance of all scales on prioritization of alternatives can be also observed in this figure. One of advantages of using this diagram is the possibility to observe variations in selection of alternatives resulting from continuous changes of scales. This could turn this method into an applicable and suitable technique for different projects. It signifies that a tool called "decision support system" can be available through constructing network and providing preliminary information as input data. This tool might be useful in different projects despite changes in significance of criteria. The prioritized project commensurate with its characteristics can be achieved by incorporating its specific information. Gradient diagram demonstrating prioritization of alternatives with respect to a scale can be evaluated in the next stage.

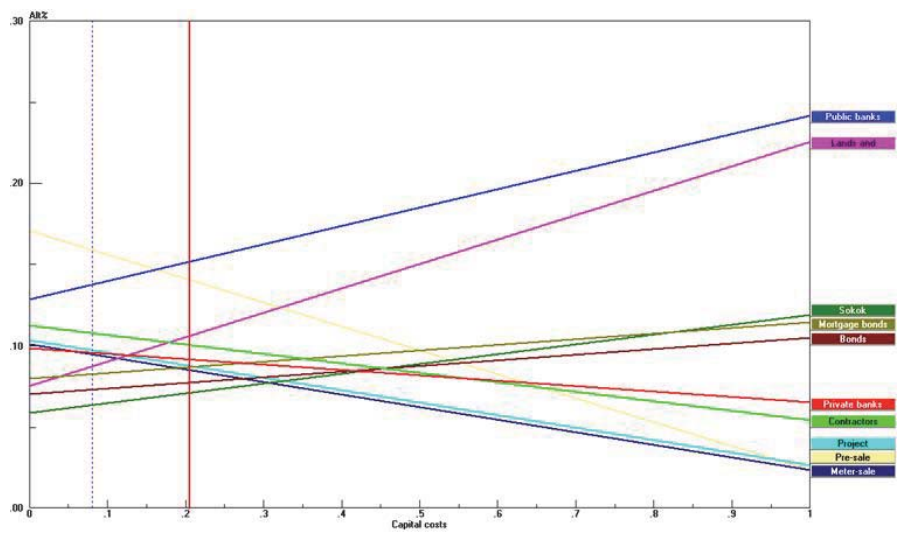

Figure 3. Gradient Sensitivity Analysis 
In this figure, each scale can be analyzed in terms of priority of alternatives and impact of any change in scale on general priority can be observed. In the diagram of above figure, all priorities are analyzed based on capital cost scale. The last diagram designated "two-dimensional plot" also illustrates priority of alternatives with respect to two criteria. This plot is divided into four segments (quarters). Ideal alternative is shown in the upper right-hand side quarter and the alternative with lowest utility is placed in lower left-hand side quarter. The alternatives shown in upper left-hand side quarter indicate that a certain decision cannot be made about these two alternatives taking into account the two specified criteria. In other words, alternatives suffer from inconsistency. Using this trend, priority of alternatives with respect to all criteria can be also observed in addition to their priority with respect to two specified criteria. In this state, each alternative will have two circles and the bigger circle is representative of priority of scale with respect to two selected criteria and the smaller circle which is connected to the larger one by a straight line represents priority of alternatives with respect to all criteria. Two criteria, namely financing cost and minimum of negative impact are shown in the figure below.

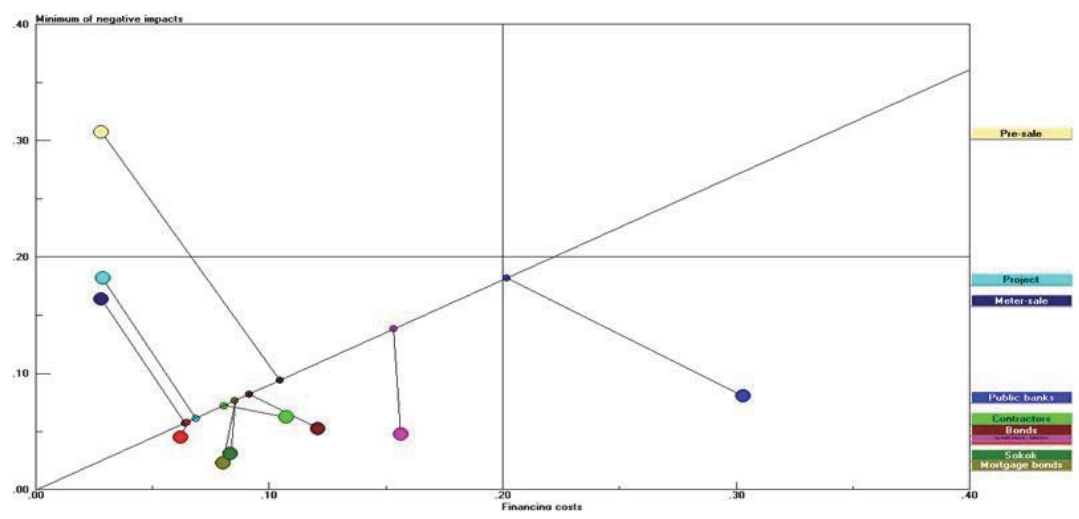

Figure 4. Two-Dimensional (2Dplot) Sensitivity Analysis

\section{Conclusion}

The objective of this paper was to help officials of Renovation Organization as supporters of understudied projects in financing of projects through fulfilling multiple and sometimes contradictory expectations of the respective organization regarding financial provision method.

In research plan of the current article, achieving this objective requires obtaining the following intermediate goals:

- Providing fundamentals of project finance

- Selection of most suitable method according to fundamentals of problem

- Analysis and complementary evaluation of these methods

- Decision-making in order to find superior scenario using superior decision-making methods in project management by ranking the alternatives

Criteria were primarily defined for evaluation of financial provision choices. First, general utility criteria of a finance method were presented. Additionally, according to research objectives, a number of criteria were incorporated into decision-making problem for evaluating the risks assigned to each provider of financial resources. These criteria were defined for distributing risks whose managements were to be transferred to external beneficiaries such as providers of financial resources as a policy of Renovation Organization. Summarization of these studies led to identification of 7 decision-making criteria taking into account the objectives of Renovation Organization. Up to this stage, the finance methods had been found but their comparison was not possible yet. For the same reason, through repeated analysis, a combination of criteria with largest impact on all finance methods was discovered. To optimize evaluation of these concepts, Analytic Hierarchy Process (AHP) method was deployed, so as to offer a suitable ranking for finance methods in accordance with the proposed criteria.

For comprehensiveness of research and its applicability in different project, it was vital to be capable of analyzing variation mechanism of prioritization with changing the proposed criteria. For this purpose, with the help of sensitivity analysis, variation behavior in ranking of different finance methods could be expressed according to criteria. For this 
purpose, different procedures of sensitivity analysis including gradient, performance, dynamic, and two-dimensional plot were investigated so that research findings can be extended to various projects.

\section{References}

Cagno, E. Caron, F. Perego, A. (2001). Multi-criteria assessment of the probability of winning in the competitive bidding process. International Journal of Project Management 19, 313-324.

El-Sawalhi, N. D Eaton, R. Rustom. (2007). Contractor pre-qualification model: State-of-the-art. International Journal of Project Management 25, 465-474.

Fight, A. (2006). Introduction to Project Finance. Oxford: Butterworth-Heinemann, An imprint of Elsevier.

Finnerty, J.D. (1996). Project Financing. New York: John Wiley \& Sons.

Gatti, S. (2008). Project Finance in Theory and Practice. San Diego, California: Elsevier.

Ghodsipour, H. (2001). Multi-Criteria Decision-Making and Analytic Hierarchy Process. Amirkabir University of Technology Publications, Tehran.

Hastak, M. (1998). Advanced automation or conventional construction process. Automation in Construction, 299-314.

Ho, W. (2008). Integrated analytic hierarchy process and its applications - A literature review. European Journal of Operational Research, 211-228.

Kamal, M. Al-Harbi, A. (2001). Application of the AHP in project management. International Journal of Project Management 19, 19-27.

Mahdi, I.M. Alreshaid, K. (2005). Decision support system for selecting the proper project delivery method using analytical hierarchy process (AHP). International Journal of Project Management 23, 564-572.

Nassar, K. Thabet, W. Beliveau, Y. (2003). A procedure for multi-criteria selection of building assemblies. Automation in Construction 12 , 543-560.

Turner, R. (2007). The Financing of Projects. In P.W. Morris, \& J. K. Pinto, The Wiley Guide to Project, Program \& Portfolio Management. John Wiley \& Sons.

Vaidya, O.S. Kumar, S. (2006). Analytic hierarchy process: An overview of applications. European Journal of Operational Research, 129.

Yescombe, E. (2002). Principles of Project Finance. San Diego, California: Academic Press- An Imprint of Elsevier. 